\title{
Educação Ambiental no ensino de ciências: enfoque para a sustentabilidade
}

\author{
Felícia Cardoso Mendes ${ }^{1}$ \\ Bianca Mendes dos Santos ${ }^{2}$ \\ Marcelo Bruno Araújo Queiroz ${ }^{3}$
}

\section{INTRODUÇÃO}

Atualmente com a abundância dos meios de informação e comunicação muito tem se discutido sobre as questões ambientais e os seus impactos no meio em que vivemos, sabemos que a escola tem um papel importante nessa questão, uma vez que ela educa cidadãos para viver em sociedade e esses assuntos relacionados ao meio ambiente precisam ser mostrados aos jovens educandos através da educação ambiental.

A importância de inserir a dimensão ambiental no processo educativo tem sido muito debatida, e há generalizada concordância sobre as contribuições do paradigma ambientalista na construção de uma nova perspectiva educacional, o qual busca educar o cidadão para gerir os bens naturais e sociais do seu ambiente e/ou torná-lo agente de transformações sociais importantes para a conservação do meio e a preservação da vida (ARAUJO, 2005).

A educação ambiental ganhou repercussão em 1977, através do documento final da Conferência de Tbilisi, na Geórgia, Jacobi (2003, p. 190) afirma que "com essa conferência inicia-se um amplo processo em nível global orientado para criar as condições que formem uma nova consciência sobre o valor da natureza e para reorientar a produção de conhecimento baseada nos métodos da interdisciplinaridade e nos princípios da complexidade. Esse campo educativo tem sido fertilizado transversalmente, $\mathrm{e}$ isso tem possibilitado a realização de experiências concretas de educação ambiental de forma criativa e inovadora por diversos segmentos da população e em diversos níveis de formação. Para que essa relação se torne cada vez mais forte é preciso que haja uma interação maior da inserção dessa temática e seus eixos na esfera da gestão escolar".

\footnotetext{
$1 \quad$ Universidade Federal do Piauí - Campus Professora Cinobelina Elvas (UFPI - CPCE) felícia_piaui@hotmail.com

$2 \quad$ Universidade do Extremo Sul Catarinense (UNESC) - biancamdossantos@gmail.com

Universidade Federal do Piauí - Campus Professora Cinobelina Elvas (UFPI - CPCE) bruno.marcelo14@hotmail.com
} 
O foco deste trabalho esta voltado para a importância de se trabalhar assuntos ambientais no ensino fundamental, dando um enfoque maior para o eixo da sustentabilidade e a primeira inteiração dos alunos com o tema, é considerável apresentar uma definição para sustentabilidade que segundo Sachs (2002, p. 8589), "o conceito de sustentabilidade existe oito dimensões da sustentabilidade que devem ser levadas em conta sendo ela social, ecológica, política (nacional e internacional), cultural, territorial, econômica e ambiental, no qual essa ultima tratase de respeitar e realçar a capacidade de autodepuração dos ecossistemas naturais."

Considera-se relevante essa investigação, pois a educação ambiental tem uma grande demanda de informação, e apontamos o ambiente escolar como permanente e principal ponto de conexão entre essas informações e os informados sendo eles alunos, para melhor entender a educação ambiental apontamos sua definição segundo o Manual Prático de Educação Ambiental (2008) conceitua a Educação Ambiental como instrumento capaz de educar o indivíduo mediante a compreensão dos principais problemas do mundo contemporâneo, possibilitando-Ihe conhecimentos técnicos e as qualidades necessárias para desempenhar uma função produtiva com vistas a melhorar a vida e proteger o meio ambiente, considerando os valores éticos

Diante do proposto, esse trabalho objetiva investigar através de alunos do oitavo ano do ensino fundamental a importância da educação ambiental e qual a visão deles sobre sustentabilidade, assim podendo analisar e discutir como esses temas são enxergados pela juventude atual e qual seus interesses sobre os mesmo, lembrando que é fundamental a inserção do eixo meio ambiente no espaço escolar.

\section{TRAJETÓRIA METODOLÓGICA DA PESQUISA DE CAMPO}

Esse trabalho foi desenvolvido na Unidade Escolar Araci Lustosa - UEAL do município de Bom Jesus situada no sul do estado do Piauí, tida como a cidade do agronegócio, onde as questões ambientais estão sempre em alta. $\mathrm{O}$ alvo de estudo foram alunos do oitavo ano, sétima serie do ensino fundamental, com idade media entre 13 a 15 anos a pesquisa foi realizada durante a aula da disciplina de Ciências, existindo a interação, auxilio e o apoio da professora regente da matéria. A escola 
estadual foi escolhida por dois motivos: a) devido à realidade enfrentada na qualidade de ensino desta escola pública e b) a necessidade de contribuir para a melhoria da aprendizagem e sensibilização dos alunos sobre os problemas ambientais presentes neste município.

Trata-se de uma pesquisa descritiva e de natureza qualitativa, oriunda de um levantamento de dados através de questionários aplicados para trinta alunos. Considera-se qualitativo, pois, para Chizzotti (2006, p. 28) "o termo qualitativo implica uma partilha densa com pessoas, fatos e locais que constituem objetos de pesquisa, para extrair desse convívio os significados visíveis e latentes que somente são perceptíveis a uma atenção sensível". E descritiva porque nos possibilita descrever o objeto indagado da pesquisa.

Para o levantamento de dados foram utilizados questionários com perguntas dicotômicas que para Marconi e Lakatos (2010, p. 187), "são aquelas que o informante escolhe sua resposta entre opções: sim e não". Foram trinta questionários respondidos individualmente sem o auxilio de material para pesquisa, pois o intuito é analisar o conhecimento prévio desses alunos em relação ao tema proposto e sua sinceridade ao responder sem influencia do meio.

Foram escolhidas três perguntas básicas e objetivas são elas: Você já ouviu falar sobre sustentabilidade? Saberia dar um conceito sobre sustentabilidade? E por fim, você acha que assuntos ligados ao meio ambiente deveriam ser mais trabalhados em sala de aula? Através das respostas destas perguntas foram realizadas as analises e elaborações de dados por meio da codificação segundo Marconi e Lakatos (2010, p. 150), é a técnica operacional utilizada para categorizar os dados que se relacionam. Mediante a codificação, os dados são transformados em símbolos, podendo ser tabelados e contados.

\section{RESULTADOS E DISCUSSÕES}

Como primeiro questionamento, temos: "Você já ouviu falar sobre sustentabilidade?". E para melhor elucidar e discutir esse resultado foi especificado na forma do gráfico 1 logo abaixo.

Gráfico1: Representa o posicionamento dos alunos se já ouviram falar sobre sustentabilidade, sim ou não. 


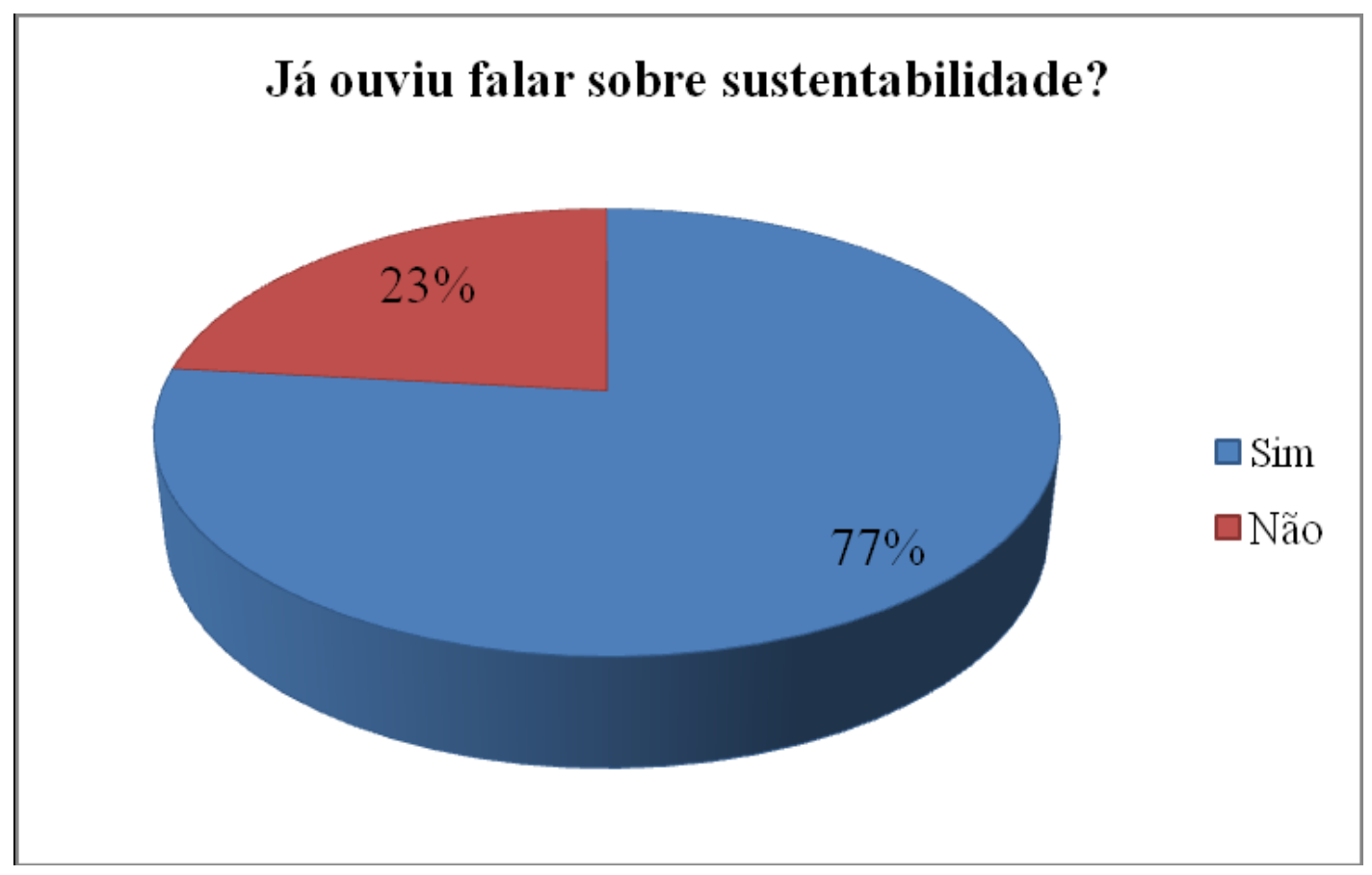

Fonte: Arquivo dos pesquisadores, 2014.

Percebemos que a grande maioria dos alunos já ouviu falar em sustentabilidade sendo um resultado positivo e benéfico que contribui com o intuito da pesquisa, porém podemos observar que $23 \%$ dos alunos nunca ouviram falar sobre esse tema, um dado preocupante onde devemos focar, pois o assunto é atualmente muito debatido e como estamos na "era da globalização" onde a facilidade de buscar informação é grande esse numero deveria ser menor ou extinto.

$\mathrm{Na}$ segunda discussão temos a seguinte pergunta: "Saberia dar um conceito sobre sustentabilidade?". Melhor representado no gráfico 2, abaixo.

Gráfico2: Representa o posicionamento dos alunos em questão se saberia dar um conceito sobre sustentabilidade, sim ou não. 


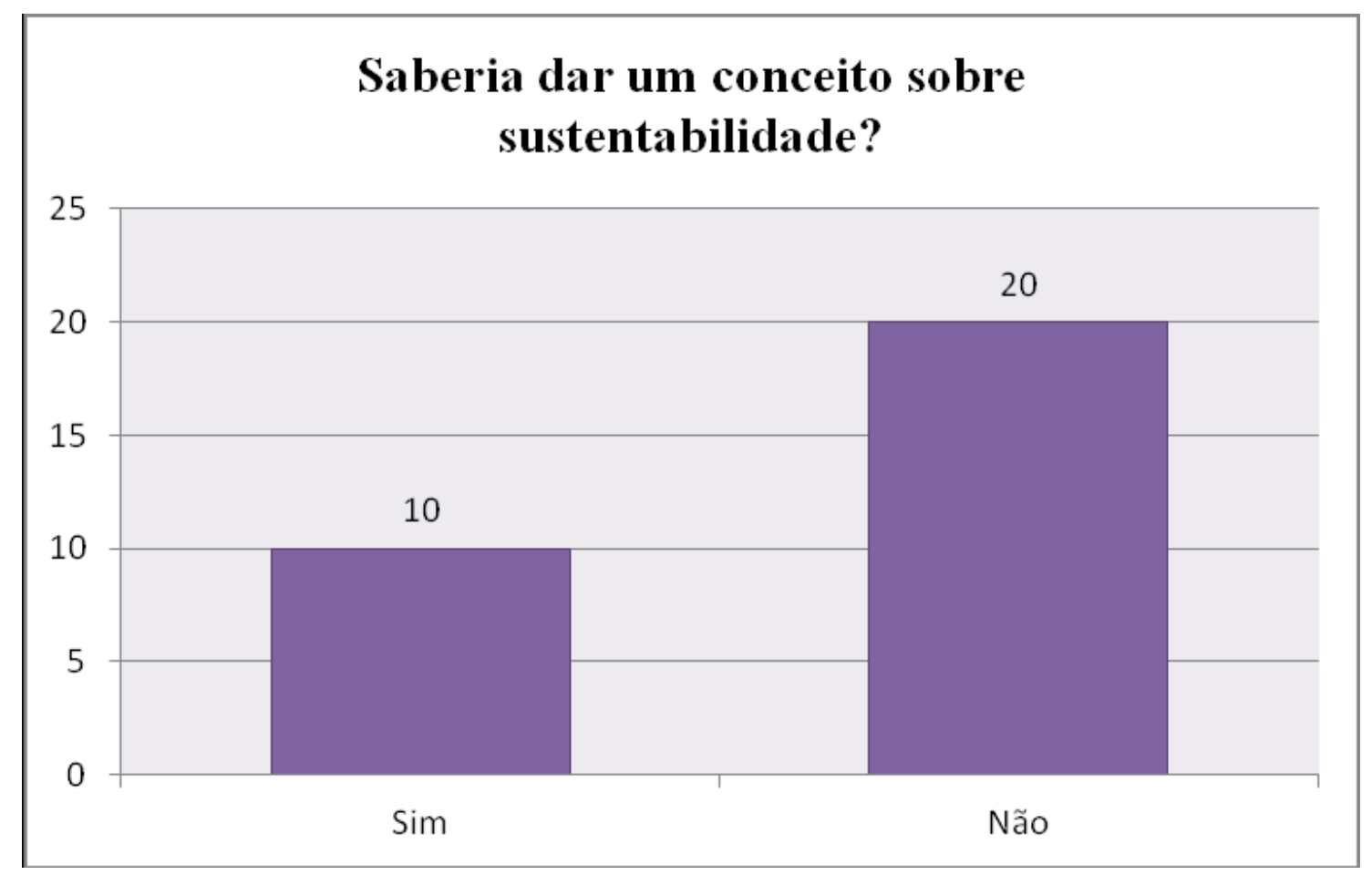

Fonte: Arquivo dos pesquisadores, 2014.

Para melhor explanar sobre o segundo gráfico, voltaremos com os dados do gráfico 1 onde vimos que cerca de $80 \%$ dos alunos já ouviram falar sobre sustentabilidade, entretanto examinando o gráfico 2, notamos que mais da metade desses alunos não conseguiriam dar uma definição. Através dessa analise somos induzidos a pensar que esses indivíduos que já escutaram sobre sustentabilidade não buscaram se informar sobre do que se trata e consequentemente quando forem abordados acerca deste tema, como foram nesta pesquisa não saberão dar uma definição.

No terceiro e último questionamento indagamos sobre educação ambiental por meio da pergunta "você acha que assuntos ligados ao meio ambiente deveriam ser mais trabalhados em sala de aula?". Surpreendentemente os 30 alunos responderam que sim, acham que assuntos sobre o meio ambiente deveriam ser mais trabalhados em sala de aula. Isso nos remete dizer que esses jovens se interessam por esse eixo, porém são pouco trabalhados, ressalvamos que é necessário que haja novas metodologias de ensino que abordem a educação ambiental em sala de aula e no âmbito escolar. Para Tiriba (2010a), afirma que a importância de as crianças desfrutarem de um ambiente bonito, arejado, iluminado pelo sol, que ofereça conforto térmico, acústico e visual. $O$ âmbito de educação 
ambiental entende-se que as crianças são seres da natureza, no qual é necessário repensar e transformar uma rotina de trabalho que supervaloriza os espaços fechados e propiciar contato cotidiano com o mundo que está para além das salas de atividades (TIRIBA, 2010b). Educação Ambiental e Educação em Ciências existe uma preocupação muito grande com os temas maiores, a relação da criança com o meio ambiente é vista como um tema menor. Mas se a gente não fizer a cabeça das gerações futuras, simplesmente não haverá geração futura (SAMPAIO et. al, 2012).

Nesse mesmo sentido as crianças possuem uma tendência à aproximação e familiaridade com seus elementos, uma afeição pelas coisas vivas, à medida que são tiradas de ambiente natural, esse contato pode não se desenvolver, gerando um desapego e indiferença em relação ao meio ambiente. Então se faz necessário colocá-las com esse universo, que estão aos seus contornos. A partir desse momento a obrigação dos docentes é passar essa integridade de preservação e conservação de todos os elementos que compõe o meio ambiente (PROFICE 2010).

\section{CONSIDERAÇÕES FINAIS}

As novas metodologias de educação de crianças e adolescentes para torná-los pessoas e cidadãs com um equilíbrio entre suas tradições e a natureza, vêm uma busca de uma maior instrução que quebre mitos e costumes. $O$ atrelamento de um aprendizado sobre o valor de uma infância escolar ligada com a natureza, trás u ma movimentação de uma educação ambiental, que coloca condições dos alunos enfrentarem e organizem suas ideias sobre as condições da natureza e do sustentável, entendendo os processos de vários recursos ambientais ao seu redor.

As curiosidades englobadas com as conversas sobre natureza, condições ambientais, afloram uma curiosidade e religa os jovens para as atividades criativas e o fazer junto, como parcerias entre eles, ensinando uma união das comunidades e do ambiental. As escolas podem ser complementadas com a educação ambiental, mostrando valores possibilitando as praticas de sustentabilidade social, ambiental, cultural, territorial, econômica, respeitando a relação à vida, tendo docentes preparados para recuperar o equilíbrio ambiental e educacional. 


\section{Agradecimentos e apoio}

Agradecemos a direção da Unidade Escolar Araci Lustosa - UEAL, juntamente com a professora de ciência do oitavo ano, sétima serie do ensino fundamental, foram peças importantes e fundamentais para a realização desta pesquisa.

\section{REFERÊNCIAS}

ARAUJO, M. I. O.; BIZZO, N. O discurso da sustentabilidade, educação ambiental e a formação de professores de biologia. Enseñanza de las ciencias VII congreso, número extra, 2005.

JACOBI, P. Educação ambiental, cidadania e sustentabilidade. Cadernos de Pesquisa, n. 118, p. 189-205. 3 mar 2003.

SACHS, I. Caminhos para o Desenvolvimento Sustentável. Rio de Janeiro: Garamond, 2002.

FENEP, Federação Nacional das Escolas Particulares. Manual prático de educação ambiental - Rio de Janeiro, dezembro de 2008.

CHIZZOTTI, A. Pesquisas em ciências humanas e sociais. 8 ed, São Paulo: Cortez, 2006.

MARCONI, M. D. A.; LAKATOS, E. M. Fundamentos de metodologia científica. 7. Ed. São Paulo: Atlas, 2010.

SAMPAIO, A. R.; TIRIBA, L. Ambientalistas e autores pelo ensino da sustentabilidade. Rev. Exame. Abril. Disponível em:

<http://exame.abril.com.br/mundo/noticias/ambientalistas-e-autores-pelo-ensino-dasustentabilidade> 2012. Acesso em: 14 abril 2015.

PROFICE, C. Percepção ambiental infantil em ambientes naturais protegidos. Tese de Doutorado, Programa de Psicologia Social da UFRN, 2010.

TIRIBA, L. Crianças da Natureza. Anais do I Seminário Nacional: currículo em movimento - Perspectivas Atuais Belo Horizonte, novembro de 2010a.

TIRIBA, L. Crianças da Natureza. Anais do I Seminário Nacional: currículo em movimento - Perspectivas Atuais Belo Horizonte, novembro de 2010b. 